\title{
Вклад Латинского монетного союза \\ и Парижской монетной конференции \\ 1867 года в становление международного \\ финансового права (МФП)
}

Шумилов Ю.В.*

В статье излагается краткий взгляд на исторические корни становления и развития двух основных институтов международного финансового права, регулирующих проблематику валютных курсов и поддержания равновесия платежных балансов. Если первоначально эти вопросы регулировались государствами односторонними и двусторонними актами, то начиная с середины XIX века начался постепенный переход на регулирование данных сфер международных финансовых отношений на многосторонней основе.

Механизмами «переключения» на многостороннее регулирование валютно-финансовых отношений государств явились Латинский монетный союз и Парижская монетная (валютная) конференция 1967 года. В статье раскрывается суть принятых в рамках союза и конференции решений и делаются выводы, касающиеся воздействия данных решений на развитие отдельных институтов международного финансового права.

Ключевые слова: международное финансовое право; Латинский монетный союз; Парижская монетная (валютная) конференция; одностороннее, двухстороннее, многостороннее регулирование международных финансовых отношений.

В современном мире практически сложилась как целостное и сложное явление глобальная валютно-финансовая система. Одним из нормативно-регулятивных инструментариев в ней является международное финансовое право ${ }^{1}$. Разразившийся в мире в 2008 году глубокий финансово-экономический кризис, продолжающийся поныне ${ }^{2}$, показал

\footnotetext{
* Шумилов Юрий Владимирович - аспирант Всероссийской академии внешней торговли (ВАВТ). yuri.shumilov@freshfields.com.

1 Лисовский В.И. Правовое регулирование международных экономических отношений. - М.,1984; Он же. Международное торговое и финансовое право. - М., 1974; Альтшулер А.Б. Международное валютное право. - М., 1984; Шумилов В.М. Международное финансовое право. - М., 2005.

${ }^{2}$ Время новостей, 22.10.2009; Ведомости, 20.10.2009; Известия, 18.11. 2009.
} 
несовершенство и самой системы отношений, и механизма ее международно-правового регулирования, привлек внимание к историческим корням и к эволюции наиболее важных институтов МФП.

Оказалось, что отдельные правовые основы современного международного финансового правопорядка - в его универсальном разрезе были заложены полтора века назад с созданием так называемого Латинского монетного союза. Уже тогда в ходе международной торговли столкнулись стратегические интересы ведущих держав в том, что касается национальных денежных систем. Проблема состояла в том, чтобы найти и юридически закрепить согласованный на многостороннем уровне способ соотнесения одной национальной валюты по отношению к другой, что дало бы возможность обеспечить платежи и расчеты в межгосударственных отношениях и в отношениях международного характера.

\section{1. От одностороннего и двустороннего регулирования к многостороннему регулированию в международных финансовых отношениях}

В докапиталистическую эпоху в Европе каждое государство (княжества, графства и прочие подобные образования феодального типа) выпускало свои деньги в форме металлических монет и, соответственно, регулировало денежное обращение собственными актами. Выпуск (эмиссия) денег - неотъемлемая черта государства, проявление суверенитета. Обмен одних монет на другие в ходе торговли на каком-то этапе производился, как правило, без вмешательства государства, на частном уровне, по законам рынка - по соотношениям, складывавшимся рыночным путем ${ }^{3}$ Главными фигурантами курсовых операций были менялы и меняльные конторы.

На частном региональном уровне первым средневековым механизмом коллективного решения проблем торговли и ее финансового обеспечения явился созданный в середине XIV века Ганзейский союз ${ }^{4}$.

Однако объективные закономерности развития экономических взаимосвязей и государственные интересы требовали: а) вмешательства государств в финансовые отношения международного характера; б) совместного - межгосударственного - поиска механизмов разрешения проблем в денежной сфере. Государства стали искать выход сначала на двусторонней, а затем и на более широкой основе.

3 Лойберг М.Я. История экономики. - М., 1997. С. 40-41.

${ }^{4}$ Г. Кёнигсбергер. Средневековая Европа: 400 - 1500 годы. - М., 2001. С. 288. 
Конкурентные отношения государств в валютно-финансовой сфере обострились в период монополистического капитализма, когда в Европе началась индустриализация. Межгосударственная конкуренция в обеспечении своей экономике (производителям) наилучших условий на внешних рынках привела за собой конкуренцию в обеспечении приоритета национальной валюты в платежно-расчетных отношениях международного характера. Столкнувшиеся в торговой и валютнофинансовой сферах государственные интересы ведущих европейских государств требовали разрешения. Способом согласования государственных интересов взаимодействующих (конкурировавших) государств стала серия двусторонних торговых договоров, которые заключили между собой Англия, Франция, Бельгия, Италия, Австрия, Швеция, Германия 5 .

Благодаря этим договорам доминировавшая в экономике Англия смогла продвинуть свои товары в другие страны и сконцентрировать у себя огромные валютные средства и запасы золота, превращаясь в мировой кредитный центр и двигатель развития сектора международных финансовых услуг. Английский фунт стерлингов де-факто превратился в «мировую валюту» своего времени. Англия односторонним актом 1816 года ввела конвертирование фунта стерлингов в золото, став родоначальницей золотомонетного стандарта. Гегемония Британской империи в мировой торговле и в валютно-финансовой сфере ущемляла интересы Франции, которая тоже претендовала на роль лидера в Европе и в мировой экономике 6 .

Закрепляя свои позиции и интересы, Англия продвигала в международно-правовых отношениях с европейскими государствами принцип свободы торговли и, соответственно, идеологию «свободы национальных валют» от государственного регулирования. Франция вынуждена была приступить к укреплению своей кредитно-банковской системы и созданию новых банков под эгидой Французского банка.

Исходя из различий в устремлениях Англии и Франции, можно сделать вывод о двух различных подходах в том, что касается правового вмешательства государственных аппаратов каждой из стран в торговую и валютно-финансовую сферы. В позиции Британской империи отразились особенности англо-саксонской правовой школы; в позиции

\footnotetext{
5 Лойберг М.Я. История экономики. - М., 1997. С. 57.

${ }^{6}$ История мировой экономики. // Под редакцией Поляка Г.Б., Марковой А.Н. - М., 2006. C. $283,302$.
} 
Франции - особенности романо-германской школы. Всё это позволило в своё время провести аналогичные различия и в подходах государств к международному праву, на которые обратил внимание известный английский юрист-международник Л.Оппенгейм ${ }^{7}$.

\section{2. Создание и роль Международного монетного союза}

Именно Франция, выступавшая за усиление роли государства в валютно-финансовой сфере, инициировала создание в 1865 году международной организации - Международного монетного союза, в которую вошли также Бельгия, Италия, Швейцария; позднее - Греция. Ряд европейских государств, не являвшихся участниками Союза, позднее ввел у себя выработанные им платежно-расчетные нормы. Международный монетный союз получил название Латинского монетного союза.

Целью Союза была унификация правил чеканки золотых и серебряных монет, поддержание устойчивого денежного обращения. В обращении свободно допускались два вида монет - из золота и серебра, а также устанавливалось соотношение между золотом и серебром: 15,5:18.

Согласно положениям учредительного акта, соответствующие учреждения государств-участников были обязаны принимать для осуществления расчетов и платежей как золотые, так и серебряные монеты. Однако в последующем рыночная стоимость серебра упала, началось обесценение серебряных монет и отток золота из стран-участниц. В целях защиты национальных валютно-финансовых систем государства прекратили чеканку серебряных монет. Механизм Латинского монетного союза «захромал» и окончательно перестал функционировать в 20-ых годах XX века (хотя юридически он распался только в конце 1926 года).

Обращает на себя внимание, что Латинский монетный союз был создан в том же году, что и Всемирный телеграфный союз (ныне - Международный союз электросвязи $)^{9}$. Примерно в это же время создавались: Всемирный почтовый союз, Международный союз мер и весов, Международный противоневольничий союз, Международный союз железнодорожных товарных сношений и еще несколько других ${ }^{10}$. Данную группу международных организаций назвали «административными

\footnotetext{
${ }^{7}$ Оппенгейм Л. Международное право. - М., 1948. // Том I, полутом 1. С. 70-71.

8 Финансово-кредитный словарь. - М., 1986.// Том.ІІ. С. 151.

9 Дипломатический словарь. - М., 1986. // Под редакций Громыко А.А. С. 213.

10 Грабарь В.Э. Материалы к истории литературы международного права в России (1647 - 1917). - M., 2005. C. 576.
} 
союзами», а их появление объяснили формированием новой отрасли международного права -международного административного права.

Под международным административным правом В.Э.Грабарь понимал нормы, с помощью которых государство охраняет на международной арене права, защищаемые на территории самого государства внутренним административным правом (например, в сферах здравоохранения - «международной заботы о здоровье»; торговли; финансов; дорог и т.п.). Как представляется, идея международного административного права может быть продуктивна и в наши дни. В таком случае это означало бы, что международное финансовое право, с точки зрения систематики международного права вообще, «вышло» из «международного административного права».

Что же касается Латинского монетного союза, то он был первой в истории международной организацией, созданной с целью многостороннего решения проблемы состыковки национальных валют друг с другом. Это был переход с двустороннего метода решения проблемы международно-правовыми средствами на многосторонний метод.

Создание Латинского монетного союза послужило толчком к формированию Парижской валютной системы и соответствующим образом направило развитие событий: во-первых, золото осталось единственным металлом, к которому государства были готовы привязывать свои валюты, чтобы определить стоимость одной национальной валюты по отношению к другой; во-вторых, обнаружилось, что монеты как единственный денежный инструмент не позволяют обеспечить нужды мировой экономики.

В результате в денежном обращении европейских государств (перед Первой мировой войной) появились бумажные деньги, а в 1867 году ведущие европейские государства согласовали на многосторонней основе подкорректированные - более совершенные - правила, регулирующие международную валютно-финансовую систему.

\section{3. Содержание Парижской валютной системы второй половины XIX века}

В 1867 году Наполеон III созвал валютную конференцию, объединившую на этот раз уже 20 наиболее заинтересованных государств. Она получила название Парижской монетной конференции. На конференции было решено, что основным валютным стандартом будет золотая монета (золото как единственная форма «мировых денег»). В 1868 году 
в Вене было подписано соглашение, положениями которого французский франк был выбран в качестве международной платежно-расчетной единицы в экономических взаимоотношениях государств-участников. Французский франк стал вытеснять английский фунт стерлингов на европейском пространстве.

Гегемонии фунта стерлингов, которую Британская империя утверждала односторонними актами, была противопоставлена гегемония французского франка, которую Франция обеспечивала коллективными - многосторонними - средствами, закрепляя ее юридически международными договорами.

Основные положения, о которых договорились государства-участники Парижской валютной системы (Латинского монетного союза), сводятся к следующему ${ }^{11}$ :

- каждая национальная валюта получала золотое содержание, т.е. как бы «привязывалась» к определенному количеству золота, что позволяло сравнивать одну валюту с другой для нужд международных расчетов и платежей, например и прежде всего в международной торговле;

- национальные валюты должны были свободно конвертироваться в золото; таким образом, валютные курсы были «плавающими», т.е. устанавливались на основе спроса и предложения - в условиях честной конкуренции на валютном рынке;

- государства и банки создавали свои резервы из золота, которые должны были служить для конвертации денег в золото по желанию предъявителя.

Государства-участники Парижской валютной системы выравнивали свои платежные балансы за счет золота. Великобритания же выравнивала платежный баланс в зоне фунта стерлингов своей национальной валютой (не теряя резервов в золоте), сохраняя при этом ее золотое содержание. Конкуренция между двумя валютами на межгосударственном уровне продолжалась. Большинство европейских государств, США, Япония, Россия перестроили свои валютные системы на золотомонетный стандарт ${ }^{12}$.

${ }^{11}$ Хасбулатов Р.И. Мировая экономика. - М., 2001.// Том II. С. 524-525; Энг М.В., Лис Ф.А., Мауер Л.Д. Мировые финансы. - М., 1998. С. 24-26; Финансово-кредитный словарь. - М., 1984. // Под редакцией Гарбузова В.Ф. С. 442-443; Mann F.A. The legal aspect of money. - Oxford. 1992. P. 3-29.

12 Борисов С.М. Золото в современном мире. - М., 2006. С. 5; Экономическая история России в XIX-XX вв.: современный взгляд. - М., 2000. // Под редакцией Виноградова В.А. С.59-60. 
Переход государств-участников на бумажные деньги (банковские, казначейские билеты), а также увеличение финансового инструментария (появление чеков, векселей в международных расчетах) - всё это объективно уменьшало роль золота. Золотом оплачивалось лишь пассивное сальдо баланса международных расчетов той или иной страны.

Привязка национальных валют к золотому стандарту вновь поднимает вопрос об экономическом (финансовом) суверенитете государств $^{13}$. С одной стороны, чеканить монеты (выпускать деньги), менять их форму, наполнение/содержание - это суверенное право государства, вытекающее из международно-правового обычая. При этом набор правоотношений, находящихся в сфере действия данного обычая, - расширяется: так, помимо чеканки монет, в состав суверенных прав государства входит и печатание бумажных денег, использование в обороте таких финансовых инструментов, как чек, вексель др.

С другой стороны, многие аспекты функционирования национальной валюты попали и продолжают попадать под регулирование средствами международного права, в том числе и само внутреннее право, касающееся эмиссии, содержания национальной валюты, валютных курсов и т.д.

Протекционистские меры, предпринятые государствами перед Первой мировой войной, ослабили эффективность Парижской валютной системы и постепенно подготовили новые изменения. Государства увеличили выпуск бумажных денег, прекратили их свободную конвертацию в золото, установили принудительные валютные курсы. Глобальная валютно-финансовая система шла к новым качественным корректировкам.

\section{4. Выводы}

Обобщая всё вышеизложенное, можно сформулировать следующие выводы.

Во-первых, становление международно-правовых норм, принципов и институтов международного финансового права как универсального явления началось с интернационализации основных проблем валютно-финансовых отношений между государствами.

Международно-правовые основы регулирования глобальной валютно-финансовой системы были заложены, главным образом, в рамках

13 Карро Д., Жюйар П. Международное экономическое право. - М., 2002. С. 453 и след.; Carreau D. Souverainete et cooperation monetaire internationale. - Paris. 1970. P. 21-107. 
Латинского монетного союза и последующими соглашениями государств-участников во второй половине XIX века.

Первыми международно-правовыми институтами, регулирующими международные финансовые отношения на многостороннем уровне, явились два института: а) международно-правовой институт валютных курсов (или валютного стандарта/валютного паритета); б) международно-правовой институт поддержания платежных балансов.

Во-вторых, международно-правовой нормативный комплекс, регулирующий валютно-финансовые отношения, проходил стадии становления и развития вслед за становлением международного торгового права. Основные этапы, закономерности и проблемы применения норм международного финансового права идентичны этапам, закономерностям и проблемам применения норм международного торгового права ${ }^{14}$. Так, международная торговая система прошла стадию «переключения» с односторонних актов на двусторонние договоры, с системы двусторонних договоров - на многосторонние соглашения; и международная финансовая система прошла эти же стадии, только с некоторым отставанием.

И в международной торговой системе, и в международной финансовой системе обнаруживается межгосударственное противостояние, столкновение интересов, конкуренция. В обеих системах принимаются меры, в основном международно-правового характера, для того, чтобы это противостояние, конкуренцию поставить в правовые рамки.

Зачастую такое противостояние принимает формы межцивилизационных отношений. В глобальной валютно-финансовой сфере на ее начальных этапах государства англосаксонской правовой школы противостояли государствам континентальной правовой школы.

В-третьих, еще до появления двусторонних и многосторонних международных договоров по валютно-финансовым вопросам в международном праве сформировался обычай, в соответствии с которым денежная эмиссия - это неотъемлемое свойство и проявление государственного суверенитета. Предметная сфера действия данного обычая постоянно расширяется. В то же время обнаруживаются некоторые тенденции, свидетельствующие о постепенном ограничении суверенных прав государств в валютно-финансовой сфере (например, признание той или иной национальной валюты - французского франка или др. - означает сознательное ограничение со стороны государства

${ }^{14}$ Шумилов В.М. Всемирная торговая организация: право и система. - М. 2006. 
собственной юрисдикции, подчинение своей валюты иностранной валюте).

В-четвертых, институты и нормы международного финансового права изначально формировались в очень жесткой привязке к стратегическим государственным интересам отдельных государств или групп государств. В результате складывавшийся в XIX веке механизм международно-правового регулирования глобальной валютно-финансовой системы оказался очень далеким от принципа справедливости.

В-пятых, российская правовая школа вообще и школа международного права в частности, а также российская дипломатия очень мало внимания уделяли и уделяют валютно-финансовым аспектам глобального мироустройства. Обращает внимание также, что в российской историографии права, в учебниках по истории государства и права практически нет материалов, касающихся международно-правовых аспектов взаимодействия государств в таких жизненно важных сферах, как валютно-финансовые отношения.

В-шестых, интересной представляется идея, изложенная В.Э. Грабарем, в части концепции международного административного права. Как представляется, эта идея требует рассмотрения и изучения применительно к современным условиям и с учетом сложившейся системы международного права.

В-седьмых, глобальная валютная система прошла в последующем через несколько этапов развития и к середине XX века мировой валютой стала национальная денежная единица Соединенных Штатов Америки. Зависимость национальных денежных систем от доллара США стала одной из причин разразившегося мирового финансово-экономического кризиса и его масштабов. Учитывая опыт Парижской валютной системы, можно было предложить рассмотреть возможность возврата государств к золотому стандарту - к привязке национальных валют к золотому содержанию. Для этого необходима новая международная конференция и новые изменения в международно-правовых основах действующего международного финансового правопорядка.

\section{Библиографический список}

Альтшулер А.Б. Международное валютное право. - М., 1984.

Борисов С.М. Золото в современном мире. - М., 2006.

Время новостей, 22.10.2009; Ведомости, 20.10.2009; Известия, 18.11. 2009 
Грабарь В.Э. Материалы к истории литературы международного права в России (1647 - 1917). - М., 2005.

Дипломатический словарь. - М., 1986. // Под редакций Громыко A.A.

История мировой экономики. // Под редакцией Поляка Г.Б., Марковой А.Н. - М., 2006.

Карро Д., Жюйар П. Международное экономическое право. - М., 2002.

Кёнигсбергер Г. Средневековая Европа: 400 - 1500 годы. - М., 2001.

Лисовский В.И. Правовое регулирование международных экономических отношений. - М.,1984.

Лисовский В.И. Международное торговое и финансовое право. М., 1974.

Лойберг М.Я. История экономики. - М., 1997.

Оппенгейм Л. Международное право. - М., 1948. // Том I, полутом 1.

Финансово-кредитный словарь. - М., 1986.// Том.II.

Хасбулатов Р.И. Мировая экономика. - М., 2001.// Том II.

Шумилов В.М. Всемирная торговая организация: право и система. - М. 2006.

Шумилов В.М. Международное финансовое право. - М., 2005.

Энг М.В., Лис Ф.А., Мауер Л.Д. Мировые финансы. - М., 1998.

Carreau D. Souverainete et cooperation monetaire internationale. $-\mathrm{Pa}-$ ris. 1970.

Mann F.A. The legal aspect of money. - Oxford. 1992. 


\section{The Contribution of the Latin Monetary Union and the Paris Monetary Conference of 1867 to the Evolution of the International Financial Law}

(Summary)

Yuri V. Shumilov*

The Author on the example of Latin monetary union and of the Paris monetary conference of 1867 shows the stages through which the states had gone from unilateral and bilateral to multilateral modes of regulation of the international finance system. In the beginning of the XIX century England dominated in world economy and tried to ensure for English pound sterling the role of «world currency». England by its unilateral act of 1816 fixed gold standard of the pound sterling. In response France initiated the creation of the international organization - the Latin monetary union in order to develop the positions the French franc in the world finance system.

In 1867 Napoleon III called the International monetary conference in Paris which decided, that all national currencies would have the gold basis. This system had been existed till the First World War. Latin monetary union and Paris International currency system were start points for the creation and development of norms and institutes of International Finance Law.

Keywords: International Finance Law; Latin monetary union; Paris monetary conference; unilateral, bilateral, multilateral modes of regulation of the international finance system; financial sovereignty of the states.

\footnotetext{
* Yuri V. Shumilov - post-graduate student of the Russian Foreign Trade Academy. yuri. shumilov@freshfields.com.
} 